\title{
Students' Study Abroad Plans: the Influence of Motivational and Personality Factors
}

\section{Manyu Li}

University of Pittsburgh

Josephine E. Olson

University of Pittsburgh

\section{Irene Hanson Frieze \\ University of Pittsburgh}

Improving the international competencies of university students is becoming an important goal for both nations and universities. On the country level, national security and globalization trends are "driving nations to place more importance on developing and recruiting human capital or brain power through international education initiatives" (Knight, 2004, p. 22). Universities also want their graduates to understand the global environment in which they will live and work. As Knight (2004) argues:

The escalating number of national, regional, international, and cultural conflicts is pushing academics to help students understand global issues and international/intercultural relationships. The mobility of the labour market and the increase in cultural diversity of communities and the workplace require that both students and academics have an increased understanding and demonstrated skills to work and live in a culturally diverse or different environment (p. 26).

A global perspective should be a part of every university student's education (Lunn, 2008), and study abroad is "one of the instruments that can be deployed as part of a strategy for internationalization of the curriculum" (Beelen 2012, p. 14). Many believe education abroad can be the best way to give students a global perspective (Beelen, 2012; Leask, 2004).

In this study we look at psychological and personality factors that influence the decisions of American students to study abroad and discuss how our findings might be used by universities to increase the number of American students who study or work abroad while undergraduates.

In the United States, the importance of international experience for students can be seen in statements made by national leaders. In 2006, U.S. Senators Richard J. Durbin and Norman B. Coleman stated in the proposed Abraham Lincoln Study Abroad Act (2006) that U.S. undergraduates should gain international experiences through study abroad to maintain the country's competitiveness. The development of multicultural competence, according to Durbin and Coleman, is to be accomplished through enhancing opportunities for U.S. college students to live abroad and to participate in study abroad programs. Likewise, the ERASMUS Program in the European Union enables European students to study abroad because "a period spent abroad not only enriches students' lives in the academic and professional fields" but also 
increases "the students' employability and job prospects" (European Commission, 2010, p.1) Many other countries also promote study abroad. In this study, we focus on U.S. students.

The number of U.S. students studying abroad is increasing. In the 2009/2010 academic year, 271,000 U.S. college students participated in study abroad programs, an increase of 88 percent over the last ten years (Chow \& Bandari, 2011). These programs usually involve studying in another country for a summer or a semester, although the number of study abroad programs for eight weeks or less rose in the last five years (McMurtie, 2009).

Although programs differ, there are some common themes on the websites of the 25 U.S. research universities that sent the most students abroad in 2011 (Chow \& Bhandari, 2011). Several websites included statements such as: "Study Abroad Changes Lives" (e.g., University of Texas-Austin, 2012). Becoming a "global citizen" or "global leader" is mentioned by others (e.g., Penn State University, 2012). Still others focus on preparing students to live in a global or diverse world (e.g., New York University, 2012). Helping students find jobs or compete in the global marketplace was emphasized by many universities (e.g., University of Southern California, 2012). A few sites went into considerable detail regarding the potential outcomes of Study Abroad. For example, the Ohio State University (2012) named five global competencies:

The ability to work effectively in international settings; awareness of and adaptability to diverse cultures, perceptions and approaches; familiarity with the major currents of global change and the issues they raise; the capacity for effective communication across cultural and linguistic boundaries; the ability to comprehend the international dimension of one's field of study.

Research on study abroad has primarily focused on the effects or outcomes of study abroad participation on the students involved in these programs (Salisbury, Paulsen \& Pascarella, 2010). For example, previous studies identified positive outcomes of study abroad such as the development of cognitive skills (Maddux \& Galinsky, 2009; Nash, 1976), self-confidence (Milstein, 2005), intercultural awareness (Langley \& Breese, 2005), second language skills (Magnan \& Black, 2007) and long-term career impact (Franklin, 2010) in the student participants. Very limited attention has been devoted to studying factors affecting students' intention and decision to study abroad (Salisbury et al., 2010).

However, from the few research studies predicting students' intentions to study abroad during college such as those done in Australia, New Zealand and the United States (e.g. Daly, 2011; Doyle et al., 2010; Goldstein \& Kim, 2006; King \& Young, 1994; Salisbury, Umbach, Paulsen \& Pascarella, 2009), it appears that such decisions are quite complex. For example, Daly (2011) suggested a model of factors affecting students' study abroad decision that includes a wide variety of international, national and institutional contextual factors as well as individual factors, such as gender, ethnicity and intercultural competencies. Therefore, looking into students' intention to study abroad will potentially help study abroad programs to more effectively market their programs and to develop programs that better fit student interests.

Deciding to participate in a program in another country involves a process of balancing potential benefits and costs of study abroad. The potential costs include not only additional financial expenses and perhaps the loss of part-time job, but also the possibility of lengthening one's years of study because of the inability to take required courses when not on campus (Paus \& Robinson, 2008). Beyond these explicit costs, there are the challenges of leaving one's comfort zones and familiar places, friends and family. For example, in a New Zealand study, Doyle et al. (2010) found that students rated 'the cost of studying overseas', 'leaving friends and family' and 'prefer to finish degree first' as major obstacle to studying overseas. 
Also, people who have high attachment to their hometown or college campus may experience negative emotions or even homesickness when going to another country (Fisher, 1989; Frieze \& Li, 2010). Such individuals feel comfortable and secure only in familiar locations (Manzo, 2003; Shumaker \& Taylor, 1983). Many study abroad participants, if not all, go through a period of acculturation and adaptation to the host countries' cultures and lifestyle (Kristjansdottir, 2009; Sobre-Denton \& Hart, 2008). This period of acculturation and adaptation can be difficult.

In order to meet the demands of a new cultural environment, students may need to develop new ways of living (Chen \& Isa, 2003; Ward \& Kennedy, 1999). This process usually brings students much anxiety and uncertainty (Gudykunst \& Hammer, 1988). In addition to these emotional struggles, students may also need to overcome communication problems that they have not had experienced before in their home country (Kim, 2001). Facing these adaptation problems, some who do not successfully adapt to the host cultures may experience psychological and physical health problems (Zheng \& Berry, 1991).

Given the many possible costs of leaving campus for participation in an educational program in another country, there must be perceived benefits of such programs that outweigh these costs. Earlier we reviewed some of the expected benefits described on university websites, but these were the universities' expectations, not the students'. In a study of Australian students' reflections on their study abroad experience, Forsey, Broomhall and Davis (2012) argued that what students reported learning "stands in stark contrast to the lofty rhetoric of their home university" (p. 129). They reported that half the students stated their priorities were to have fun, travel and make friends, and they saw study abroad as a break from serious work. Students did report a greater sense of confidence and independence and about half thought they were more openminded as a result of their study abroad. In a study of students at Oregon State University who had not yet done study abroad, the strongest influences on their interest in studying abroad were the desires: to experience living in another culture; to travel and have adventures; personal growth; and learning more about the country. Somewhat less important were: learning a foreign language and future career (King $\&$ Young, 1994). Kasravi (2009), after reviewing a number of studies on study abroad outcomes, reported that the benefits students perceived included such things as personal development and autonomy, identity development, flexibility, cross-cultural competence, increased international knowledge, motivation and career development.

In the process of balancing benefits and costs, we propose that motivation and personality in the student influence such processes. Therefore, we are interested in the fundamental motivational and personality factors relating to students' study abroad intention. We believe that these personality factors represent the major reasons why students do or do not go abroad to study. Specifically, the present study focuses on students' achievement motivation, neophilia, migrant personality and desire to help by comparing students high and low in desire to study abroad.

\section{Achievement motivation}

Achievement motivation is defined as the desire to work hard and to do things well (McClelland, 1961; 1987). It is associated with higher confidence in one's abilities (McClelland, 1987). Numerous studies have demonstrated relations between students' achievement motivation and their academic-related behaviors (e.g. Bogler \& Somech, 2002; Halamandaris \& Power, 1999). Deciding whether to participate in study abroad is an academic decision and thus may be affected by achievement motivation. Specifically, students high in achievement motivation tend to study hard and take on challenging academic tasks (McClelland, 1987). 
Since study abroad can be a challenging academic task that requires students to plan ahead and to overcome different adaptation challenges, students who are high in achievement motivation may also have higher desire for study abroad. Previous research found significant relations between students' study abroad decision making process and other academic variables, such as students' high school involvement and attitudes in taking college courses and reading literacy (Salisbury et al., 2010). They found that students who were more involved in high school learning, had more interests in reading literacy and were taking more diverse college courses were more likely to want to study abroad. Since achievement motivation is found to relate to students' academic-related behaviors, this motive may also have an impact on students' decision to study abroad.

Other studies have shown that people who are higher in achievement motivation are "more restless and avoid routine" (McClelland, 1987, p.249). This might suggest that students with higher achievement motivation want to avoid routine and avoid staying in a mundane study environment. They may seek opportunities to study in a more diverse environment on their way to finishing their degree. Study abroad, being one of the ways for them to avoid routine, may thus be more attractive to students who are higher in achievement motivation.

A positive relationship between achievement motivation and participation in study abroad has been found in at least one research study. Schroth and McCormack (2000), in studying nearly 400 U.S. students who had previously studied abroad, found that these students had higher achievement motivation than those of their counterparts who had not studied abroad. However, as Schroth and McCormack (2000) measured levels of achievement motivation in students who had already participated in a study abroad program, it is unclear if the difference in achievement motivation was due to their original high need for achievement, the highly selective nature of study abroad program, or a result of their study abroad experiences. Examining students' desire to study abroad before actually participating in such a program will provide us with a better idea of how achievement motivation functions as a factor affecting students' desire to study abroad.

\section{Neophilia}

Another factor that may play a role in influencing students' study abroad intention is neophilia, a novelty-seeking personality. Neophilia is defined as the "appreciation for and even a desire to have, fresh, new experiences" or "a love of the new" (Janda, 2001, p.190). The original scale measuring neophilia was developed by Walker and Gibbins (1989). They found that people who scored high on neophilia were more willing to accept personal and social changes. Also, these high neophilic people were found to have more unorthodox tastes and were more likely to take risks to gain new experiences. On the other hand, those who scored low on neophilia were afraid of new information and thus would tend to avoid new things. People who are high in neophilia were also found to like to taste new things (Dawley, 2006), try novel food (Sabry, 1996), or take risks (Lepp \& Gibson, 2003). In other words, people who have neophilic personality perform more sensation-seeking or novelty-seeking behaviors.

Although not directly testing with a formal measure of neophilia, research on study abroad has indicated an indirect association. For example, there is a relationship between love/fear of new things and study abroad intention. Salisbury et al. (2009, 2010), in studying more than 2,000 college students, found that both male and female students with higher study abroad desire were more willing to interact with new people who are from different backgrounds and who have different values than they do. In another study, Goldstein and Kim (2006) found that students with higher intention to study abroad were more open to 
learning a new language and experienced less anxiety when encountering a new culture. Bakalis and Joiner (2004) found that Australian students who chose to go on a study abroad program had higher openness to different cultures than students who did not, which is one of the characteristics of neophilia. Naffziger, Bott, \& Mueller $(2008,2010)$ identified "fear of unknown", that is, fear associated with new experiences, as a factor keeping students from going to study abroad. In other words, students who experienced less fear of new experiences were more likely to want to study abroad. These research findings all point toward the possibility that the love of experiencing new things, or neophilia, influences students' study abroad intention.

\section{Migrant personality}

People who are highly mobile are believed to have a migrant personality or mobile personality (Boneva $\&$ Frieze, 2001; Frieze \& Li, 2010). This same personality has been labeled as a "mobicentric" (Jennings, 1970) or "pioneering personality" (Morrison \& Wheeler, 1976). People with high migrant personality are believed to be "predisposed" to migrate, instead of being merely influenced by situational factors (Boneva $\&$ Frieze, 2001). This could be expressed in its most extreme form by emigrating from one location to another, but it might also be manifested in a desire to travel for vacations or other reasons (Frieze \& $\mathrm{Li}, 2010$ ). Although study abroad is regarded as an academic experience for students who want to explore a new culture or learn another language, it, at the same time, contains a travel component and relocation that requires a fondness for mobility. Therefore, we suggest that people who are interested in study abroad should also have this migrant personality.

\section{Desire to help}

Finally, study abroad intention may relate to students' desire to help others. This may include their desire to help their country, society and people around them. In the Abraham Lincoln Study Abroad Act (2006), U.S. Senators Durbin and Coleman emphasized that students should study abroad, not merely because of potential benefits for themselves, but also because of general benefits for the country. They further explained, "One of the best ways to do this [preparing internationally-informed U.S. citizens] is through study abroad. As such, it must be an integral part of a complete college education and the centerpiece of a national effort to ensure that the next generation of Americans is ready for life and leadership in the 21 st century. Study abroad is more than an education issue - it is a national security and foreign policy issue" (NAFSA, 2006, para 3). These statements raise study abroad to a national issue, and students who want to contribute to the country or to have an influence in society may respond to this call and thus be even more eager to study abroad. Societal concern and the desire to have an influence in the society are characteristics of people with high desire to help (Frieze \& Boneva, 2001; Peterson \& Stewart, 1993).

Although no direct link between helping and desire to study abroad was identified, in their study on students' study abroad choice process, Salisbury et al. (2009) found that students' past involvement in the community and school was related to desire to study abroad. One of the items measuring this past involvement was students' previous participation in community service or volunteering, among other past school involvement items such as participation in extracurricular activities and talking to teachers outside class. This item of community service showed high factor loading (.653) in the factor analysis conducted on 
all items believed to relate to study abroad (Salisbury et al., 2009). This may suggest that wanting to help does play a role in students' desire to study abroad.

One reason contributing to this association between a desire to help others and interest in study abroad might be that some study abroad programs are service based. Such programs allow students to participate and help the hosting community in different ways. For example, the International Partnership for ServiceLearning and Leadership (IPSL) is a program specifically dedicated to combining academic studies and volunteer service for students who go study abroad (for details of the program, refer to http://www.ipsl.org/). Depending on where the study abroad program is, students are provided with voluntary service opportunities, such as helping children with rehabilitation needs, helping abandoned children, teaching street children, helping in homes for the elderly, and serving women in prostitution and their children. Similar to the IPSL is the Vira I. Heinz Program (VIH, for details of the program, refer to http://www.viraheinz.pitt.edu/). This program combines academic experiences, leadership training and community services into a semester-long study abroad experience for students in 16 universities and colleges in Pennsylvania, Ohio and West Virginia. Another example of such program is the Amizade Global Service Learning Program (http://amizade.org). Its service-learning courses allow students to live in and serve the local community while taking courses for academic credits during their semester abroad. More traditional study abroad programs may also offer the opportunity for service or unpaid internships with nongovernment organizations (NGOs).

Although students may not know the exact details of these programs, students may foresee having these experiences while they are abroad. Therefore, students who have a higher desire to help may want to fulfill this interest by participating in study abroad programs. Study abroad programs may thus attract students who are high in desire to help. In other words, being higher in the desire to help may be associated with a higher desire to study abroad if students interpret the question about study abroad intention as offering helping opportunities in other countries. In this study, we include a several items measuring desires to help others and to help society to see how such attitudes relate to desires to study abroad.

\section{Hypotheses}

We hypothesized that students with high desire to study abroad will be higher in achievement motivation, neophilia, migrant personality and desire to help. Since desires to study abroad have been found to be higher in women than men (Dessoff, 2006, Salisbury et al., 2010), and more U.S. women study abroad than U.S. men (Chow \& Bhandari, 2011), we control for gender in the tests of these hypotheses.

\section{Method}

\section{Sample Characteristics}

A total of 555 participants were recruited. All students were in the Introduction to Psychology class. Since this class is a general university requirement, it had students from diverse majors and backgrounds. Among these students, 171 (31\%) were male and 383 (69\%) were female. The nine participants under age 18 and the 14 participants over 22 were excluded to restrict the age range of our sample to 18-22 years old. One of the female participants did not answer the item on the major outcome variable, study abroad intention. Therefore, she was taken out from the analysis. Since we were only interested in students who had 
high or low desire in study abroad, students who did not have a clear preference for study abroad were excluded. After excluding the 100 participants who did not have clear preference, our final sample consists of 431 participants, of whom 92 (21\%) were male and 339 (79\%) were female. Most of them were first year students $(\mathrm{N}=379,71 \%)$.

\section{Measures}

Study Abroad Intention. Study abroad intention was measured using a single item, "I expect to take advantage of the opportunity to study in a different country while I am in college." Participants rated this statement on a 5-point Likert scale from 1 (strongly disagree) to 5 (strongly agree). Participants who answered 1 to 2 were categorized as the low desire group, while participants who answered 4 to 5 were categorized as the high desire group. As we noted above, we were mainly interested in comparing students who had obvious interest or lack of interest in study abroad; therefore, we included students who responded 1-2 (low desire) and 4-5 (high desire), but excluded students who did not show any preference (3). As a result, $92(17.3 \%)$ were in the low desire group and $339(64 \%)$ were in the high desire group. Table 1 shows the distribution of study abroad intention of the participants by gender.

Gender differences in study abroad intention were tested using Chi-square. Results showed that men and women responded differently to study abroad intention, with women being more interested than men $\chi^{2}(1, N=531)=29.02, p<.01$. This further supports the need to control for gender in our main analysis looking at predictors of interest in study abroad.

Achievement motivation. Achievement motivation was measured by Helmreich and Spence's (1978) scale. The 23-item scale was rated on a 5-point Likert scale from 1 (strongly disagree) to 5 (strongly agree). The scale has been widely used in previous research (e.g., Frieze, Hansen, \& Boneva, 2006). It is believed to be a scale that closely follows McClelland's definition of achievement motivation (Frieze et al., 2006). Sample items include: "I find satisfaction in doing things as well as I can"; "Once I undertake a task, I persist"; and "I enjoy being in competition with others." For the full scale for achievement motivation as well as other scales used in the research, see http://sites.google.com/site/friezewebsite/cross-cultural-surveyof-work-and-gender-attitudes. The Cronbach's alpha for this study was .80. The items were averaged to create the score for achievement motivation.

Neophilia. Neophilia was measured using Walker and Gibbins' (1989) scale. The scale is a 38-item scale rated on a 5-point Likert Scale from 1 (strongly disagree) to 5 (strongly agree). Sample items are "I like change" and "People who know me seem to think that I am into strange and unusual things". Cronbach's alpha for this scale was .73. Items were averaged to create the score.

Migrant Personality. Migrant personality was measured by seven items tapping students' travel and migration desire. Appendix A lists all the items being included. Three items asked their migration intention right after they graduate, and three items measured their migration desire at any point in their life. Finally, one item, "I enjoy traveling" measured participants' desire for traveling. The items were rated on a 5-point scale from 1 (strongly disagree) to 5 (strongly agree). Cronbach's alpha for the migrant personality scale is 0.79. Items were averaged to create the score.

Desire to Help. Desire to help was measured with a scale consisting of five items from Schmidt and Frieze's (1997) power motivation helping desire subscale. This subscale consists of the following items measuring participants' desire to help the world and people around them: "I am very concerned over the welfare of others"; "I would like for my ideas to help people"; "I hope to one day make an impact on others or the world"; "when people I know are trying to solve a problem, my gut instinct is to offer them helpful 
suggestions"; and "it would be very satisfying to be able to have impact on the quality of others' lives". We added one more item - "young people have an obligation to make our society better" to the subscale. We wanted to ensure we measured participants' general attitude toward making the society a better place. All six items were rated on a 5-point Likert scale from 1 (strongly disagree) to 5 (strongly agree). Cronbach's alpha for the desire to help scale was .73. Items were averaged to create the score.

\section{Results}

To test our hypothesis that higher achievement motivation, neophilia, migrant personality and desire to help relate to higher study abroad intention, a MANOVA testing the main effects of the hypothesized variables on study abroad desire, controlling for gender, was employed. As shown in Table 2, the main effect of gender is only significant for desire to help, $\mathrm{F}(1,426)=6.31, p<.05$, with women scoring higher than men.

A significant multivariate main effect for study abroad desires was found, Wilks' Lambda $=.83$, $\mathrm{F}(4,423)=22.04, p<.01$. As predicted, main effects for all hypothesized variables were all significant. As shown in Table 3, the Participants who had high study abroad desire had significantly higher achievement motivation than low study abroad desire participant, $\mathrm{F}(1,426)=8.48, p<.01$. Similarly, high study abroad desire participants had significantly higher neophilia than low study abroad desire participants, $\mathrm{F}(1$, 426) $=1.91, p<.01$. Participants with high study abroad desire were also higher in migrant personality than those with low study abroad desire, $\mathrm{F}(1,426)=37.92, p<.01$. Finally, high study abroad desire participants also had a higher desire to help than low desire participants, $\mathrm{F}(1,426)=2.24, p<.01$.

A significant interaction effect was found for achievement motivation by gender interaction on study abroad desire, $\mathrm{F}(1,426)=6.94, p<.01$. Post-hoc contrast analysis revealed that in male participants, high study abroad desire is related to significantly higher achievement motivation, $\mathrm{F}=12.4, p<.01$. However, achievement motivation is not a significant factor in female's study abroad desire. Figure 1 illustrates the interaction effect.

The hypothesized effects of personality and motivational factors on students' study abroad desire were generally supported. Specifically, we found that students who had higher study abroad desire also scored higher on neophilia, migrant personality and desire to help, in an analysis that controlled for gender. The interaction effect in gender and achievement also showed that men's achievement motivation relates to their study abroad desire.

\section{Discussion}

The present study adds to previous research knowledge on the personality profile of students with high versus low study abroad desire. Previous research identified a choice process of students' study abroad desires (e.g. Salisbury et al., 2009), but the factors within students' personality affecting the choice process were not clear. The present study thus makes a step forward by identifying important predispositional factors within students that affect their intention. Being able to identify these factors should help educators and researchers understand the characteristics of students wanting to study abroad. Understanding student characteristics may assist educators in developing different types of programs and better promotional strategies to attract a wider variety of students to participate in study abroad programs. 
One application of our results is on offering study abroad programs that match with students' needs. Our data indicate that students who have high desire to help are more interested in study abroad. However, we did not find much emphasis on service on the main pages of the University websites we examined. Our findings suggest that educators designing school-sponsored study abroad programs may want to add a service element to their programs. This may not only attract more students but may provide them with a more meaningful experience. Ogden (2006) argued that a service element can get students out of their "student ghetto" to really learn something. He wrote:

Engagement within the local community presents students with opportunities to interact with people they might not otherwise meet on a daily basis, or the "hidden populations" within the mainstream society. Such activities can offer students exposure to a range of groups such as the elderly, disabled, homeless, or minority sub-cultures. Rather than focusing on social change and activism, the emphasis here is better placed on engaging students in learning from these people, to be taught by them, so as to develop a more holistic, subjective understanding of the host culture (p. 107).

Universities that want to attract exchange students might consider offering volunteer activities for their international students and listing them on their website. The home Study Abroad office may also encourage students going on exchange or direct enrollment programs, who are interested in community service, to actively seek out such opportunities when they get there.

In addition to targeting students with high desire to help through community service options that we discussed above, educators should orient their promotional materials toward students who are highly neophilic and highly mobile. This can be done by highlighting how students can make use of the opportunity to enjoy excitement and diverse experiences through the program. However, it does appear that many universities and colleges today are already adopting these strategies as students seem to expect excitement in study abroad. In order to avoid making these study abroad programs appear to be 'just for fun' and to underscore the serious educational value that such programs provide, institutions should emphasize that the excitement and satisfaction one can get from study abroad is from learning new things, meeting new people and gaining competence in another language.

Our data suggested that people who are less neophilic are less likely to want to go to study abroad. Therefore, it is important that schools try to get these non-neophilic students involved. Highlighting other benefits of study abroad (career development, international expertise, etc.) and offering more diverse study abroad programs (service-based or career-based ones that can include internships) may help to reduce the biased population in study abroad program we see. For example, a relatively short, highly structured study abroad program led by a faculty member from the home institution may help non-neophilic students overcome their fear of going abroad (Olson \& Lalley, 2012).

The significant interaction of gender and achievement motivation in predicting study abroad desire suggests that the effect of achievement motivation on study abroad desire is only significant for men, but not for women. In other words, women's desire to study abroad was not affected by their motivation to achieve, but only affected by their neophilic characteristic, migrant personality and desire to help others. This finding may be explained by the women's high score on desire to help in our sample $(M=4.03)$. Although our sample included students with diverse majors and backgrounds, our data showed that the female students in our sample were highly altruistic. This high motive for caring and helping other people may have led to a 
focus on others over oneself in making decisions. Therefore, females with low achievement motivation may still want to study abroad because of their desire to help.

The interaction effect also suggests that men's and women's study abroad intention may be influenced by different personality factors. There has been a long concern over the gender imbalance in study abroad programs, with many more U.S. females than males participating (Salisbury et al., 2010). This may be due, in part, to the perception of study abroad as a feminine activity. To encourage more men to participate, our data suggest that institutions should emphasize the opportunity to achieve. For example, students who are able to gain international experiences are now considered to be more capable by employers (Naffziger et al., 2008, 2010). Employers also view study abroad as an important and positive experience (Salisbury et al., 2010). Highlighting these facts may attract more men who have high achievement motivation to participate.

Although King and Young (1994) found college men were less interested in study abroad in general than college women, the men were more interested in internships than women ( 49 percent to 37 percent). Institutions may want to consider incorporating some career-related activities in their study abroad programs, such as career-related internships. As an example, the business school at the University of Pittsburgh recently began a summer unpaid foreign internship program for undergraduates in China, France, Germany and Spain. The program includes coursework on the country and language training as well as a 12-week internship. Of the 46 students who participated in 2012, 52 percent were men.

Our interaction effect also points to another contribution of the present study, which is the need to consider gender. Although it was well-known that there are more women than men joining study abroad programs, previous research tended to assume that the underlying decision-making patterns for men and women were the same. Our study indicates the need to look at gender differences.

Although we see the potential for great value in study abroad, there is apparently an opposing view related to gender, which was described in a paper by Kinginger (2009). She wrote that study abroad is considered by many to be the equivalent of the "Grand Tour" for wealthy young women. She further argued "the feminization of study abroad further serves to associate overseas education with lack of academic rigor and professional purpose" (p. 219). She went on to describe the fact that many of today's study abroad programs for U.S. students do not encourage them to engage with the local community but keep them in a bubble with other Americans. In addition, with the widespread availability of cell phones and social networks, the students no longer need to distance themselves from their families and friends. She asserted: "They may choose to screen out their local environment and the people in it, in favor of extensive interactions through an electronic umbilical cord, with people they already know" (p. 223).

Further research should examine the relationship among psychological factors, gender and the types of study abroad programs. For example, perhaps there is a better gender balance in programs that are career focused and offer an internship.

In conclusion, the present study identified several important psychological factors affecting students' study abroad intentions. It also offered some ideas as to how institutions may improve and promote their study abroad programs. However, one should note that our study is based on a U.S. sample. Therefore, some of the factors affecting U.S. students may not apply to other cultures. Future research may review studies from different countries to see the cultural differences in study abroad motivations, or conduct crosscultural studies with participants from different countries. This kind of cross-cultural study might help to design programs that can attract students from different parts of the world. 


\section{References}

Abraham Lincoln Study Abroad Act (2006), U.S. House of Representatives, Second Session. Retrieved from http://www.govtrack.us/congress/billtext.xpd?bill=s109-3744.

Beelen, J. (2012). The long wait: research the implementation of internationalization at home. In J. Beelen $\&$ H. de Wit. (Eds.) Internationalisation Revisited: New Dimensions in the Internationalisation of Higher Education (pp. 9-21). Centre for Applied Research on Economics and Management. Retrieved from: http://www.carem.hva.nl/wp-content/uploads/2012/07/Internationalisation-Revisited-CAREM2012.pdf\#page $=12$

Bakalis, S. \& Joiner, T. A. (2004) Participation in tertiary study abroad programs: the role of personality. International Journal of Educational Management, 18, 286-291.

Bogler, R., \& Somech, A. (2002). Motives to study and socialization tactics among university students. The Journal of Social Psychology, 142, 233-248.

Boneva, B. S., \& Frieze, I. H. (2001). Toward a concept of a migrant personality. Journal of Social Issues, 57, 477-492.

Chen, L., \& Isa, M. I. (2003). Intercultural communication and cultural learning: The experience of Japanese visiting students in the U.S. The Howard Journal of Communications, 14, 757-796.

Chow, P. \& Bhandari, R. (2011). Open Doors 2001 Report on International Educational Exchange. New York: Institute of International Education.

Daly, A. (2011). Determinants of participating in Australian university student exchange program. Journal of Research in International Education, 10, 58-70.

Dawley, H. (2006, June 18). The disorder of these times, neophilia [Article]. Retrieved from http://www.medialifemagazine.com/cgi-bin/artman/exec/view.cgi?archive=226\&num=5439.

Dessoff, A. (2006). Who's not going abroad? International Educator, 15(2), 20-27.

Doyle, S., Gendall, P., Meyer, L., Hoek, J., Tait, C., McKenzie, L., \& Loorpang, A. (2010). An investigation of factors associated with student participation in study abroad. Journal of Studies in International Education, 14, 471-490.

European Commission. (2010). The ERASMUS Programme-studying in Europe and more. Retrieved from http://ec.europa.eu/education/lifelong-learning-programme/doc80_en.htm

Fisher, S. (1989). Homesickness, cognition, and health. East Sussex, UK: Lawrence Erlbaum Associates.

Forsey, M., Broomhall, S. \& Davis, J. (2011). Broadening the mind? Australian student reflections on the experience of overseas study. Journal of Studies in International Education, 16, 128-139. Doi: $10.1177 / 1028315311407511$.

Franklin, K. (2010). Long-term career impact and professional applicability of the study abroad experience. Frontiers: The Interdisciplinary Journal of Study Abroad, 19, 169-190.

Frieze, I. H., \& Boneva, B. S. (2001). Motivation to help. In A. Y. Lee-Chai \& J. A. Bargh (Eds.), The use and abuse of power: Multiple perspectives on the causes of corruption (pp. 75-92). Philadelphia: Taylor \& Francis.

Frieze, I. H., Hansen, S. B., \& Boneva, B. (2006). The migrant personality and college students' plans for geographic mobility. Journal of Environmental Psychology, 26, 170-177.

Frieze, I. H. \& Li, M. (2010). Mobility and personality. In S. Carr (Ed.), The psychology of mobility in a global era (pp.87-104). New York: Springer. 
Goldstein, S. B., \& Kim, R. I. (2006). Predictors of US college students' participation in study abroad programs: A longitudinal study. International Journal of Intercultural Relations, 30, 507-521.

Gudykunst, W. B., \& Hammer, M. R. (1988). Strangers and hosts: An uncertainty reduction based theory of intercultural adaptation. In Y. Y. Kim \& W. B. Gudykunst (Eds.), Cross-cultural adaptation: Current approaches (pp. 106-139). Newbury Park, CA: Sage.

Halamandaris, K. F., \& Power, K. G. (1999). Individual differences, social support and coping with the examination stress: A study of the psychosocial and academic adjustment of first year home students. Personality and Individual Differences, 26, 665-685.

Helmreich, R., \& Spence, J. (1978). The Work and Family Orientation Questionnaire: An objective instrument to assess components of achievement motivation and attitudes toward family and career. JSAS Catalogue of Selected Documents in Psychology, 8, 35.

Institute of International Education (2010). Study abroad by U.S. students slowed in 2008/09 with more students going to less traditional destinations [Press Release]. Retrieved from http://www.iie.org/en/WhoWe-Are/News-and-Events/Press-Center/Press-Releases/2010/2010-11-15-Open-Doors-US-StudyAbroad

Janda, L. (2001). The psychologist's book of personality tests. New York: John Wiley \& Sons, Inc.

Jennings, E. E. (1970). Mobicentric man. Psychology Today, 4(2), 34-36, 70-72.

Kasravi, J. (2009). Factors influencing the decision to study abroad for students of color: Moving beyond the barriers (Doctoral Dissertation). Retrieved from http://www.ciee.org/conference/past/documents/JinousKasravi.pdf.

Kim, Y. Y. (2001). Becoming intercultural: An integrative theory of communication and cross-cultural adaptation. Thousand Oaks, CA: Sage.

King, L. J. \& Young, J. A. (1994). Education for the 21st century. Die Unterrichtspraxis/ Teaching German, 27, 77-87. Retrieved from http://www.jstor.org/stable/3531477.

Kinginger, C. (2010). American students abroad: Negotiation of difference? Language Teacher, 43, $216-227$.

Knight, J. (2004). Internationalization remodeled: definition, approaches, and rationales. Journal of Studies in International Education, 8, 5-31.

Kristjansdottir, E. S. (2009). Invisibility dreaded and desired: Phenomenological inquiry of sojourners' cross-cultural adaptation. Howard Journal of Communications, 20, 129-146.

Langley, C. S., \& Breese, J. R. (2005). Interacting sojourners: A study of students studying abroad. The Social Science Journal, 42, 313-321.

Leask, B. (2004). Internationalisation outcomes for all students using information and communication technologies. Journal of Studies in International Education, 8, 336-351.

Lepp, A. and Gibson, H. (2003). Tourist roles, perceived risk, and international tourism. Annals of Tourism Research, 30, 606-624.

Lunn, J. (2008). Global perspectives in higher education: Taking the agenda forward in the United Kingdom. Journal of Studies in International Education, 12, 231-254.

Maddux, W. W., \& Galinsky, A. D. (2009). Cultural borders and mental barriers: The relationship between living abroad and creativity. Journal of Personality and Social Psychology, 96, 1047-1061.

Magnan, S. S., \& Back, M. (2007). Social interaction and linguistic gain during study abroad. Foreign Language Annals, 40, 43-61.

Manzo, L. C. (2003). Beyond house and haven: Toward a revisioning of emotion relationships with places. 
Journal of Environmental Psychology, 23, 47-61.

McClelland, D. C. (1961). The achieving society. Princeton, NJ: Van Nostrand.

McClelland, D. C. (1987). Human motivation. Glenview, IL: Scott, Foresman.

McMurtrie, B. (2009). Study abroad programs diversify as their popularity grows. The Chronicle of Higher Education, 56, A24. Retrieved from http://chronicle.com/article/Study-Abroad-Diversifies-as/49143/.

Milstein, T. (2005). Transformation abroad: Sojourning and the perceived enhancement of self-efficacy. International Journal of Intercultural Relations, 29, 217-238.

Morrison, P. A., \& Wheeler, J. P. (1976). The image of 'elsewhere' in the American tradition of migration (Paper no. 5729). Santa Monica, CA: RAND Corporation.

Naffziger, D. W., Bott, J. P., \& Mueller, C. B. (2008). Factors influencing study abroad decisions among college of business students. International Business: Research, Teaching and Practice, 2, 39-52.

Naffziger, D. W., Bott, J. P., \& Mueller, C. B. (2010). Study abroad: Validating the factor analysis of student choices. International Business: Research, Teaching and Practice, 4, 72-81.

NAFSA: The National Association of International Educators (2006). Legislation introduced to dramatically expand study abroad among American college students. Retrieved from http://www.nafsa.org/publication.sec/periodicals/policybriefs/pb-vol1-4/

Nash, D. (1976). The personal consequences of a year of study abroad. Journal of Higher Education, 47, 191-203.

New York University. (2012). Global. Retrieved from http://www.nyu.edu/global.html.

Ogden, A. C. (2006). Ethnographic inquiry: Reframing the learning core of education abroad. Frontiers: The Interdisciplinary Journal of Study Abroad, 13, 87-112. Retrieved from:

http://www.frontiersjournal.com/frontiersjournalvolXIII.htm.

Olson, J. E. \& Lalley, K. (2012). Evaluating a Short-term, First-year Study-abroad Program for Business and Engineering Undergraduates: Understanding the Student Learning Experience. Journal of Education for Business, 87, 325-332.

Ohio State University. (2012). Opening the Door to Your Future. Retrieved from: http://oia.osu.edu/goingabroad/opening-the-door.html

Paus, E., \& Robinson, M. (2008). Increasing study abroad participation: Faculty make the difference. Frontiers: The Interdisciplinary Journal of Study Abroad, 17, 33-49.

Penn State University. (2012), Global Penn State. Retrieved from http://www.global.psu.edu/global/.

Peterson, B. E., \& Stewart, A. J. (1993). Generativity and social motives in young adults. Journal of Personality and Social Psychology, 65, 186-198.

Sabry, Z. I. (1996). Anthropological view of food and health. Asia Pacific Journal of Clinical Nutrition, 5 , 117.

Salisbury, M. H., Paulsen, M. B., \& Pascarella, E. T. (2010). To see the world or stay at home: Applying an integrated student choice model to explore the gender gap in the intent to study abroad. Research in Higher Education, 51, 615-640.

Salisbury, M. H., Umbach, P. D., Paulsen, M. B., \& Pascarella, E. T. (2009). Going global: Understanding the choice process of the intent to study abroad. Research in Higher Education, 50, 119-143.

Schmidt, L. C., \& Frieze, I. H. (1997). A mediational model of power, affiliation and achievement motives and product involvement. Journal of Business and Psychology, 4, 425-446.

Shumaker, S. A., \& Taylor, R. B. (1983). Toward a clarification of people-place relationships: A model of 
attachment to place. In N. Feimer, \& E. S. Geller (Eds.), Environmental psychology: Directions and perspectives (pp. 219-256). New York: Praeger.

Schroth, M.L., \& McCormack, W.A. (2000). Sensation seeking and need for achievement among studyabroad students. The Journal of Social Psychology, 140, 533-535.

Sobre-Denton, M., \& Hart, D. (2008). Mind the gap: Application-based analysis of cultural adjustment models. International Journal of Intercultural Relations, 32, 538-552.

University of South Carolina. (2012). Study Abroad Office. Retrieved from: http://studyabroad.sc.edu/

University of Texas-Austin. (2012). Study Abroad Office. Reasons to Study Abroad. Retrieved from: http://world.utexas.eud/abroad

Walker, I. \& Gibbins, K. (1989) Expecting the unexpected: an explanation of category width. Perceptual and Motor Skills, 68, 715-724.

Ward, C., \& Kennedy, A. (1999). The measurement of sociocultural adaptation. International Journal of Intercultural Relations, 23, 659-678.

Zheng, X., \& Berry, J. W. (1991). Psychological adaptation of Chinese sojourners in Canada. International Journal of Psychology, 26, 451-470. 
Table 1. Distributions of participants' response to the item "I expect to take advantage of the opportunity to study in a different country while I am in college" by gender

\begin{tabular}{llll}
\hline & Men & Women & Chi-square (df=1) \\
& N (\%) & N (\%) & \\
\hline Strongly disagree & $14(8.7)$ & $21(5.7)$ & \\
Disagree & $28(17.4)$ & $29(7.9)$ & \\
Neither agree nor disagree & $36(22.4)$ & $64(17.3)$ & \\
Agree & $48(29.8)$ & $91(24.7)$ & \\
Strongly agree & $35(21.7)$ & $164(44.4)$ & $29.02^{\star \star}$ \\
Total & 161 & 369 & \\
\hline
\end{tabular}

${ }^{* *} p<.01$

Table 2. Gender differences on hypothesized predictors of study abroad intentions

\begin{tabular}{lcc}
\hline & $\begin{array}{c}\text { Men } \\
(\mathrm{N}=124) \\
\text { Mean }\end{array}$ & $\begin{array}{c}\text { Women } \\
(\mathrm{N}=305) \\
\text { Mean }\end{array}$ \\
\hline Achievement motivation & 3.74 & 3.77 \\
Neophilia & 2.98 & 2.92 \\
Migrant Personality & 3.13 & 3.10 \\
Desire to help* & 3.86 & 4.03 \\
\hline$*<.05$ & &
\end{tabular}

Table 3. Means of factors relating to low versus high study abroad intention.

\begin{tabular}{|c|c|c|}
\hline & $\begin{array}{c}\text { Low Study } \\
\text { Abroad } \\
\text { Desire } \\
(\mathrm{N}=92) \\
\text { Mean }\end{array}$ & $\begin{array}{c}\text { High } \\
\text { Study } \\
\text { Abroad } \\
\text { Desire } \\
(\mathrm{N}=339) \\
\text { Mean } \\
\end{array}$ \\
\hline Achievement motivation $\star \star \#$ & 3.69 & 3.82 \\
\hline Neophilia ** & 2.89 & 3.04 \\
\hline Migrant Personality ** & 2.74 & 3.49 \\
\hline Desire to help ** & 3.85 & 4.04 \\
\hline
\end{tabular}


Figure 1. The effect of achievement motivation on study abroad desire by gender 


\section{Appendix A. Migrant Personality items}

1. Once I complete my education here at the University, I would like to go back to my hometown to work (reversed scored)

2. Once I complete my education here at the University, I expect to move to another part of the U.S.

3. Once I complete my education here at the University, I expect to leave the United States and move to another country

4. If I am given the opportunity, I would like to live in a region of the country that I have never been to before.

5. If I am given the opportunity, I would like to live in a different country at some points of my life.

6. If I am given the opportunity, I would like to immigrate to another country.

7. I enjoy traveling. 